\title{
Energy absorption capability of thin-walled aluminium tubes under crash loading
}

\author{
P. Khalili ${ }^{1}$, F. Tarlochan ${ }^{2}$, A.M.S. Hamouda ${ }^{2}$ and K. Al - Khalifa $^{3}$ \\ ${ }^{1}$ Center for Innovation and Design, Universiti Tenaga Nasional, Malaysia \\ ${ }^{2}$ Department of Mechanical and Industrial Engineering, \\ Qatar University, Doha, Qatar \\ ${ }^{3}$ Qatar Road Safety Studies Center, Qatar University, Doha, Qatar \\ Email: faris.tarlochan@qu.edu.qa \\ Phone: +974 44034367 and +974 44034301
}

\begin{abstract}
This paper investigates the interaction of design factors such as tube thickness, tube length, and tube cross-sectional aspect ratio, along with friction and impacting mass on crashworthiness parameters such as specific energy absorption contact time, peak force and crush distance. The impact velocity is assumed to be constant at $15 \mathrm{~m} / \mathrm{s}$. The focus is on rectangular aluminium tubes and the analysis was carried out by using a validated finite element model. The analysis shows that the factors are not independent of each other and there is some degree of interaction between them. It was found that the trigger mechanism is a very important design factor to be included in the design of thin-walled tubes for energy absorption applications. The effect of the friction coefficient was found to be insignificant and finally, based on the interactions, it can be concluded that the most effective design would be a larger tube with small wall thickness, and a larger aspect ratio to avoid buckling.
\end{abstract}

Keywords: Impact load; thin-walled tubes; energy absorption; trigger mechanism.

\section{INTRODUCTION}

In any collision between vehicles, kinetic energy has to dissipate in a controlled manner that will protect the occupants in the vehicle from bodily injuries or fatalities. Thin-walled tubular metallic structures are very efficient as energy absorbers and can be easily designed into a vehicle's frontal protection system [1]. These metallic thin-walled structures have the capability to convert the kinetic energy to strain energy by irreversible plastic deformation. Most of the reported works in the literature on such tubes have used mild steel as the base material for understanding the energy absorption efficiency. However, in the light of efficient fuel economics, aluminium as a lightweight material is gaining popularity [2]. In terms of the works reported on aluminium as an efficient energy absorber, most of them can be categorized as the following investigations; (a) effect of cross-sectional geometry [3-7], (b) effect of trigger mechanisms [8-12], (c) effect of boundary conditions [13-16], (d) effects due to innovative designs [6, 16-23], (e) effect of failure mechanism and (f) effect of fillers such as foams [24-27]. For the crosssectional geometries, a buckling initiator using inertia force for a hat-shaped cross-section improved the energy absorption for aluminium tubes [3]. For square tubes, the response is very dependent on impact velocity, and the deformation at transition from progressive collapse to buckling increases with increasing impact velocity due to inertia forces [4]. It has been proven that deviating from standard square or rectangular cross-sectional tubular 
designs to a polygonal section in the form of a hexagon or octagon can further enhance the energy absorption capabilities of such aluminium tubular structures [5]. In a separate study [6], thin-walled structures consisting of spherical shells merging into conical frusta of various geometries showed collapse mechanisms that proved them to have potential as energy absorbing devices.

Trigger mechanisms are used to initiate progressive folding on thin tubular structures and at the same time to lower the maximum peak force. A trigger mechanism can be explained as a "defect" in the structure which causes the structure to fail first at the location of the trigger. In a study by Lee et al.[8], it was found that trigger mechanisms that are located at the pitch length of the folding wave enhance the energy absorption capability of the tube. In a study investigating grooves on tubes [9], it was found that the folding process of the tubes could be controlled by the introduction of grooves with different distances and hence achieved the desired load uniformity. Similar findings were obtained in a separate study [10] investigating longitudinally grooved square tubes. Zhang et al.[11] have designed a new trigger mechanism attached to the structure and the novel design has proven to improve the energy absorption and lower the initial peak force. Trigger mechanisms in the form of circumferential strain concentration on corrugated tube surfaces have shown good design initiatives towards enhancing energy absorption [12]. In most of the reported works pertaining to the energy absorption of aluminium tubes, there are no discussions or findings relating to the interaction between design factors on the desired responses. The objective of this study is to investigate the effect of the interaction of design factors on the energy absorption capabilities of aluminium tubes.

\section{FINITE ELEMENT ANALYSIS}

The finite element model of the tube consists of shell elements with an element size of 5 $\mathrm{mm}$ (after sensitivity analysis of mesh size). The tube was constrained at the base (boundary condition). The impactor was designed as a rigid element and was only allowed to move along the longitudinal axis of the tube. The impactor has an initial velocity of 15 $\mathrm{m} / \mathrm{s}$. This is to simulate the axial loading condition. The material used is aluminium 6063 T5, where the strain rate has no significant influence on the hardening behaviour up to $10^{3} \mathrm{~s}^{-1}$ [28-30]. The mechanical properties are the Young's modulus E $=71000 \mathrm{MPa}$, yield stress $\sigma=200 \mathrm{MPa}$ and the density $\rho=2700 \mathrm{~kg} / \mathrm{m}^{3}$. The nominal strain-stress curve is obtained from the following reference. The hardening modulus is defined for the nominal strain-stress curve, 500 and $209 \mathrm{MPa}$ for the true strains $\varepsilon_{\mathrm{p}}<0.04$ and $\varepsilon_{\mathrm{p}}>0.04$, respectively. Besides, imperfections are considered to trigger the asymmetric buckling mode of the structure [29]. In this step, the experiment set-up in the literature [2] of the square tube subjected to axial loading was modelled and the results were compared. The square tube had the width $23.7 \mathrm{~mm}$, length $146 \mathrm{~mm}$ and wall thickness $1.14 \mathrm{~mm}$. Comparison of the contact time, crush distance, initial peak force and energy absorption between the FE model and the experimental tests [29] was carried out. Table 1 displays the loading condition of the structures and it can be seen that there is a satisfactory agreement between the FE model and experiment for impact energy, and the deflections of all structures had a good correlation with the experimental test. Comparison of the contact time between the experiment and FE model is depicted in Table 2, proving the close correlation of crush time. Figure 1 also demonstrates a reasonable trend of contact time versus dynamic force for the N-1-B between the FE model of this study and the experiment. Figure 2 represents the deformed profile of the experimental and numerical tests by and the FE model of this study, which illustrates the number and location of the 
folds. For N-1-B, N-2-C and N-3-D, lobes were placed in the lower part of the crushed tubes. For N-4-E, the wrinkles matched well with the experiment, in which two big wrinkles formed, one in the upper and another in the lower part of the structure. The upper lobe crushed more than the lower one.

Table 1. Comparison between experimental and finite element analysis.

\begin{tabular}{lllllll}
\hline Specimen & $\mathrm{V}(\mathrm{m} / \mathrm{s})$ & $\mathrm{M}(\mathrm{kg})$ & \multicolumn{2}{c}{ Energy absorption (J) } & \multicolumn{2}{c}{$\begin{array}{c}\text { Deflection } \\
(\mathrm{mm})\end{array}$} \\
\hline & & & Ref. [2] & $\begin{array}{c}\text { FE model } \\
\text { (current study) }\end{array}$ & Ref. [2] & $\begin{array}{c}\text { FE model } \\
\text { (current study) }\end{array}$ \\
\hline N-1-B & 15.91 & 0.95 & 120 & 120 & 6.2 & 6 \\
N-2-C & 35.35 & 0.44 & 275 & 275 & 20.9 & 21.7 \\
N-3-D & 64.62 & 0.103 & 215 & 212 & 9.2 & 11.1 \\
N-4-E & 91.35 & 0.103 & 431 & 428 & 25.7 & 25.1 \\
\hline
\end{tabular}

Table 2. Comparison between the contact time (seconds) for the experimental and FE model.

\begin{tabular}{llll}
\hline Model & $\begin{array}{l}\text { Impact contact time } \\
\text { of experiment }(\mathrm{sec}) \\
{[29]}\end{array}$ & $\begin{array}{l}\text { Impact contact time } \\
\text { of numerical test } \\
(\mathrm{sec})[2]\end{array}$ & $\begin{array}{l}\text { Impact contact } \\
\text { time (sec) of FE } \\
\text { model (current } \\
\text { study) }\end{array}$ \\
\hline N-1-B & 1.06 & 1.20 & 1.05 \\
N-2-C & 1.56 & 1.83 & 1.88 \\
N-3-D & 0.50 & 0.56 & 0.6 \\
N-4-E & 0.83 & 0.82 & 0.75 \\
\hline
\end{tabular}

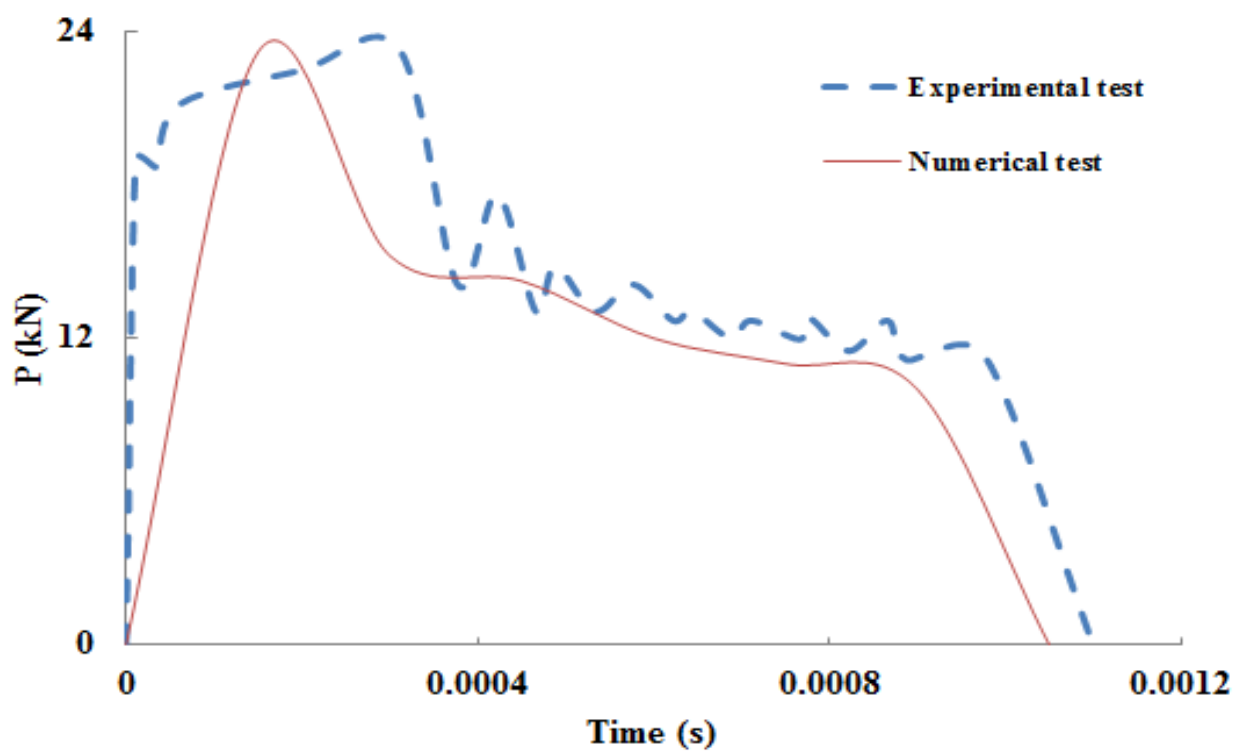

Figure 1. Comparison of dynamic force vs impact time for the FE model of this study and the experiment [29]. 


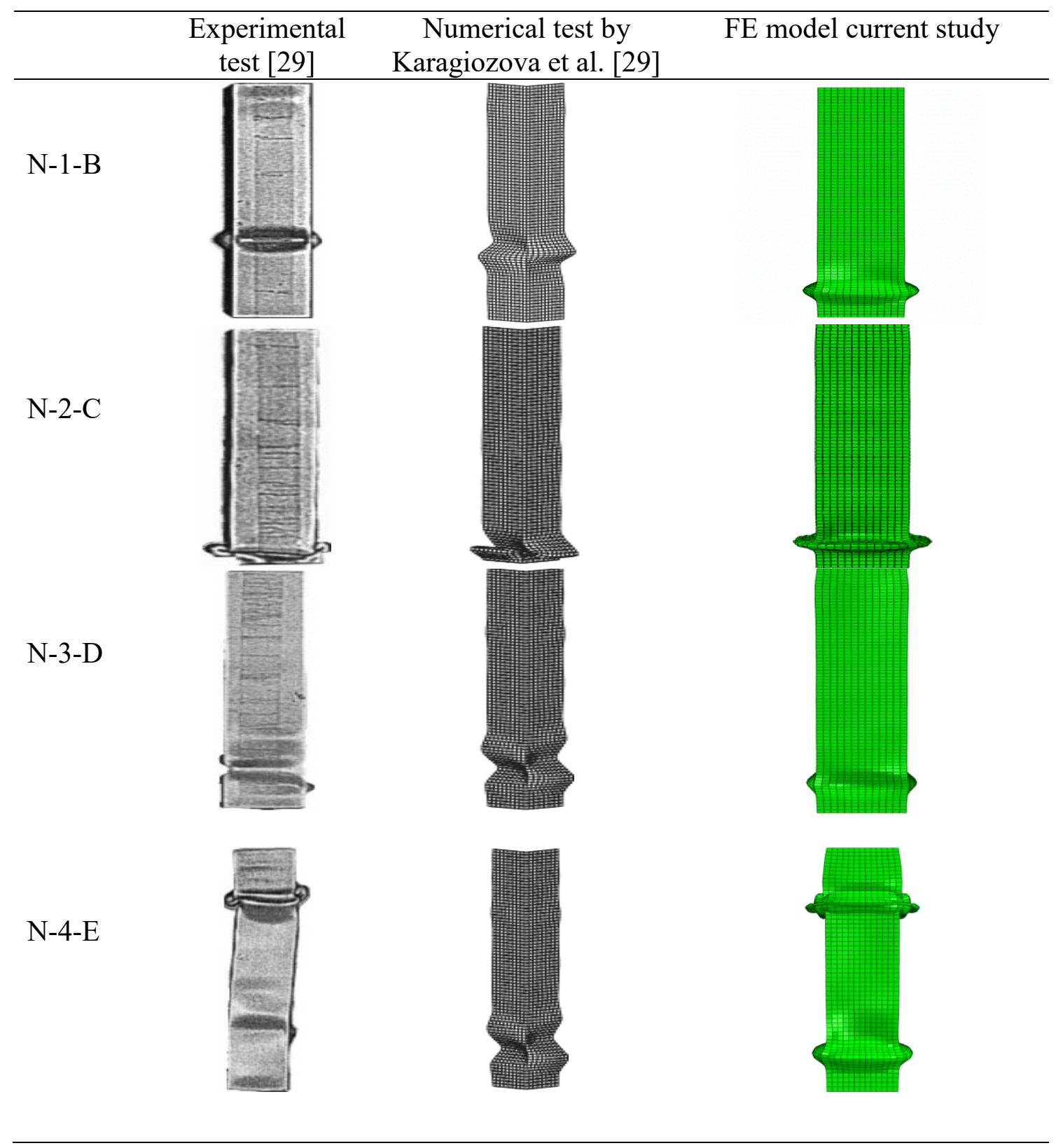

Figure 2. Deformation mode of square tubes from experimental and FE model of [29] and in comparison to FE model of current study.

\section{MAIN EFFECTS OF INDIVIDUAL FACTORS}

The influences of different lengths, aspect ratios, thicknesses, friction coefficients and trigger mechanisms on the structure's crushing response were studied. Table 3 indicates the design of experiment taking into consideration various design parameters. The initial velocity $15 \mathrm{~m} / \mathrm{s}$, taken as a typical amount for automobile accidents, was considered constant and the mass was varied from 5 to $10 \mathrm{~kg}$. The thickness differed from 1 to $3 \mathrm{~mm}$, the friction coefficient from 0.1 to 0.5 and the length from 150 to $200 \mathrm{~mm}$. In the parametric study, two rectangular areas were considered. While one width of the sectional area was kept at $50 \mathrm{~mm}$ for both sectional areas, the other width was assumed to be 100 and $25 \mathrm{~mm}$. The aspect ratio is defined as the ratio of the constant width $(50 \mathrm{~mm})$ with respect to the variable widths of 100 and $25 \mathrm{~mm}$, corresponding to the aspect ratio of 0.5 
and 2 respectively. Figure 3(a) represents the trigger model for the aspect ratio of 0.5 including 12 holes, in which 3 holes were applied in each face of the tube. For the aspect ratio 2, Figure 3(b) displays a total of 8 holes, 3 for each of the two larger faces and 1 for each of the two smaller faces of the rectangular tube. The diameter of each hole was 10 $\mathrm{mm}$ and the distance of the holes from the top rib was also taken as $10 \mathrm{~mm}$. The middle hole in each face of both rectangular areas was assigned in the central position of each face. Also, the only hole in the smaller face of the rectangular tube with aspect ratio 2 was made in the centre of the top rib. For those faces including 3 holes, the left and right holes were employed at a distance of $10 \mathrm{~mm}$ from the left and right sides. Figure 3(c) pictures the right view of the tube with the aspect ratio 0.5 .

(a)

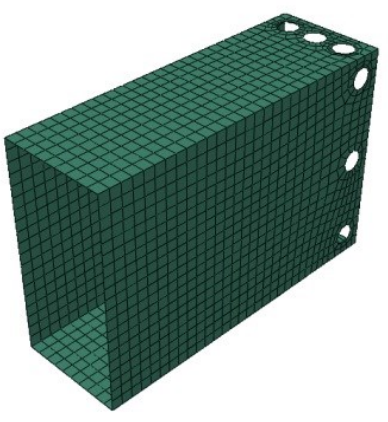

Figure 3. (a) Trigger model with aspect ratio 0.5 and 12 holes, (b) Trigger model with aspect ratio 2 and 8 holes, (c) right view of specimen

\section{RESULTS AND DISCUSSION}

The findings can be summarized based on analysing Figures 4-6. These figures detail the main effect of individual factors on the output response, taking into account the mean values of the data (statistical method). In Figure 4, the response on the crush distance based on the input parameters is shown for both the non-trigger and trigger models. In summary, the crush distance is influenced heavily by the tube wall thickness and impacting mass. This is because as the mass increases, the kinetic energy of the impactor increases. Hence, the tube is able to absorb more energy. The tube is analogous to a spring. When more mass is added to the spring, the spring deforms further. For the thickness, as the thickness increases, the rigidity of the tube towards deformation increases, resulting in lower energy absorption. In terms of contact time, as shown in Figure 5, thickness and the impacting mass are the dominating factors. As the mass increases, the tube deforms further, hence increasing the contact time. As the thickness increases, the rigidity of the tube causes the impactor to bounce off more quickly, resulting in a smaller contact time. Finally, the specific energy absorption (SEA), as shown in Figure 6, is influenced by all parameters. In short, most of the input parameters have an effect on the output response. Besides this, as in other findings published in the literature [30], the trigger mechanism is an important parameter to include when designing crash absorbers. Here is a generalized finding based on these interaction plots for tubes with a trigger mechanism: 
Table 3. Design of Experiment detailing the various design variables.

\begin{tabular}{|c|c|c|c|c|c|c|c|}
\hline Tubes & Models & $\begin{array}{l}\mathrm{L} \\
(\mathrm{mm})\end{array}$ & $\begin{array}{l}\text { Aspect } \\
\text { ratio }\end{array}$ & $\begin{array}{l}\text { Wall thickness, } \mathrm{t} \\
(\mathrm{mm})\end{array}$ & $\begin{array}{l}\text { Friction } \\
\text { coefficient }\end{array}$ & $\begin{array}{l}\mathrm{V} \\
(\mathrm{m} / \mathrm{s})\end{array}$ & $\begin{array}{l}\mathrm{M} \\
(\mathrm{kg})\end{array}$ \\
\hline \multirow{17}{*}{$\begin{array}{l}\text { Non- } \\
\text { triggers }\end{array}$} & R-02 & 150 & 0.5 & 1 & 0.1 & 15 & 10 \\
\hline & $\mathrm{R}-14$ & 150 & 0.5 & 3 & 0.5 & 15 & 5 \\
\hline & $\mathrm{R}-26$ & 150 & 0.5 & 3 & 0.1 & 15 & 10 \\
\hline & $\mathrm{R}-34$ & 150 & 0.5 & 1 & 0.5 & 15 & 5 \\
\hline & $\mathrm{R}-44$ & 150 & 0.5 & 1 & 0.1 & 15 & 5 \\
\hline & $\mathrm{R}-8$ & 150 & 2 & 3 & 0.5 & 15 & 10 \\
\hline & $\mathrm{R}-16$ & 150 & 2 & 1 & 0.1 & 15 & 5 \\
\hline & $\mathrm{R}-18$ & 150 & 2 & 1 & 0.5 & 15 & 10 \\
\hline & $\mathrm{R}-29$ & 150 & 2 & 3 & 0.1 & 15 & 10 \\
\hline & $\mathrm{R}-3$ & 200 & 0.5 & 1 & 0.1 & 15 & 10 \\
\hline & R-9 & 200 & 0.5 & 3 & 0.5 & 15 & 10 \\
\hline & $\mathrm{R}-19$ & 200 & 0.5 & 3 & 0.1 & 15 & 10 \\
\hline & $\mathrm{R}-27$ & 200 & 0.5 & 1 & 0.5 & 15 & 5 \\
\hline & $\mathrm{R}-30$ & 200 & 0.5 & 3 & 0.5 & 15 & 5 \\
\hline & $\mathrm{R}-39$ & 200 & 0.5 & 3 & 0.1 & 15 & 5 \\
\hline & $\mathrm{R}-4$ & 200 & 2 & 1 & 0.1 & 15 & 10 \\
\hline & $\mathrm{R}-5$ & 200 & 2 & 3 & 0.1 & 15 & 10 \\
\hline \multirow{23}{*}{ Triggers } & $\mathrm{R}-6$ & 200 & 2 & 3 & 0.5 & 15 & 5 \\
\hline & $\mathrm{R}-10$ & 200 & 2 & 1 & 0.5 & 15 & 10 \\
\hline & $\mathrm{R}-11$ & 200 & 2 & 3 & 0.1 & 15 & 5 \\
\hline & $\mathrm{R}-20$ & 200 & 2 & 1 & 0.5 & 15 & 5 \\
\hline & $\mathrm{R}-01$ & 150 & 0.5 & 1 & 0.5 & 15 & 10 \\
\hline & R-33 & 150 & 0.5 & 3 & 0.5 & 15 & 10 \\
\hline & R-42 & 150 & 0.5 & 3 & 0.5 & 15 & 5 \\
\hline & R-47 & 150 & 0.5 & 3 & 0.1 & 15 & 5 \\
\hline & R-48 & 150 & 0.5 & 1 & 0.1 & 15 & 5 \\
\hline & $\mathrm{R}-13$ & 150 & 2 & 3 & 0.5 & 15 & 10 \\
\hline & $\mathrm{R}-25$ & 150 & 2 & 1 & 0.1 & 15 & 10 \\
\hline & R-32 & 150 & 2 & 3 & 0.1 & 15 & 5 \\
\hline & R-46 & 150 & 2 & 1 & 0.1 & 15 & 5 \\
\hline & $\mathrm{R}-15$ & 200 & 0.5 & 1 & 0.5 & 15 & 10 \\
\hline & $\mathrm{R}-17$ & 200 & 0.5 & 3 & 0.1 & 15 & 10 \\
\hline & $\mathrm{R}-24$ & 200 & 0.5 & 1 & 0.5 & 15 & 5 \\
\hline & $\mathrm{R}-35$ & 200 & 0.5 & 1 & 0.1 & 15 & 10 \\
\hline & R-45 & 200 & 0.5 & 1 & 0.1 & 15 & 5 \\
\hline & R-07 & 200 & 2 & 3 & 0.5 & 15 & 10 \\
\hline & $\mathrm{R}-12$ & 200 & 2 & 3 & 0.5 & 15 & 5 \\
\hline & $\mathrm{R}-21$ & 200 & 2 & 3 & 0.1 & 15 & 5 \\
\hline & R-28 & 200 & 2 & 1 & 0.1 & 15 & 10 \\
\hline & R-31 & 200 & 2 & 1 & 0.5 & 15 & 5 \\
\hline
\end{tabular}




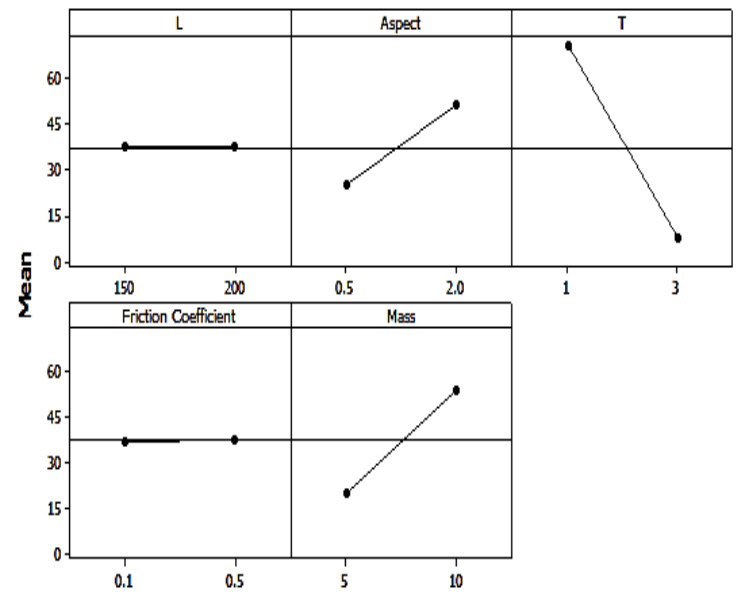

(a)

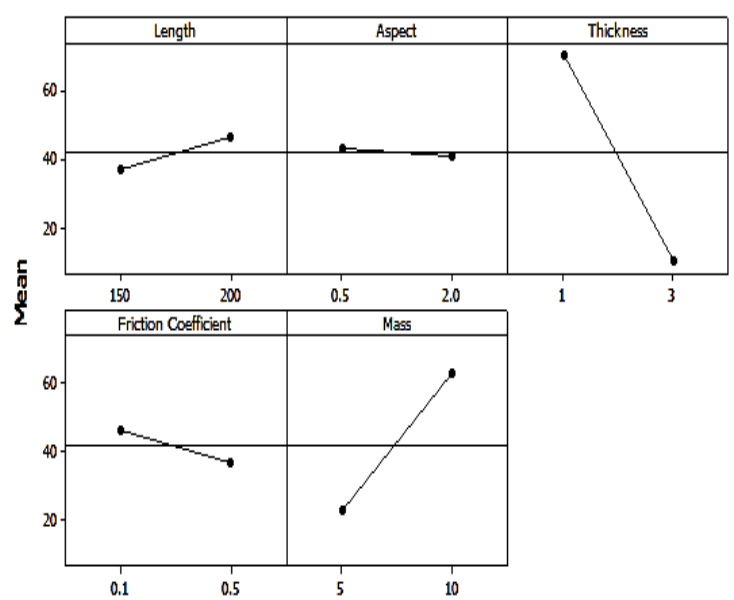

(b)

Figure 4. Main effects plot for crush distance response for: (a) no trigger, (b) with trigger.

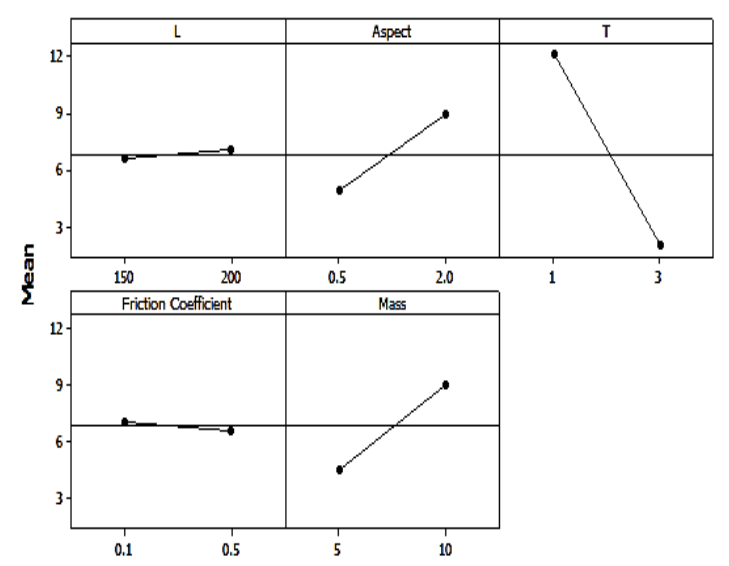

(a)

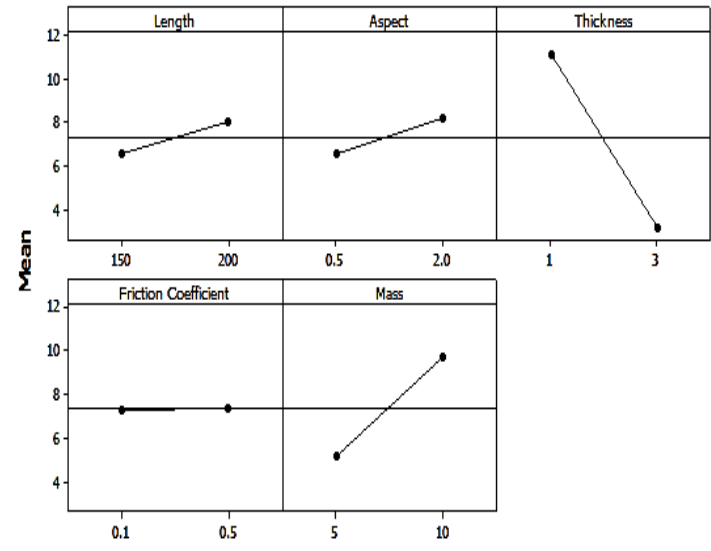

(b)

Figure 5. Main effects plot for contact time response for: (a) no trigger (b) with trigger.

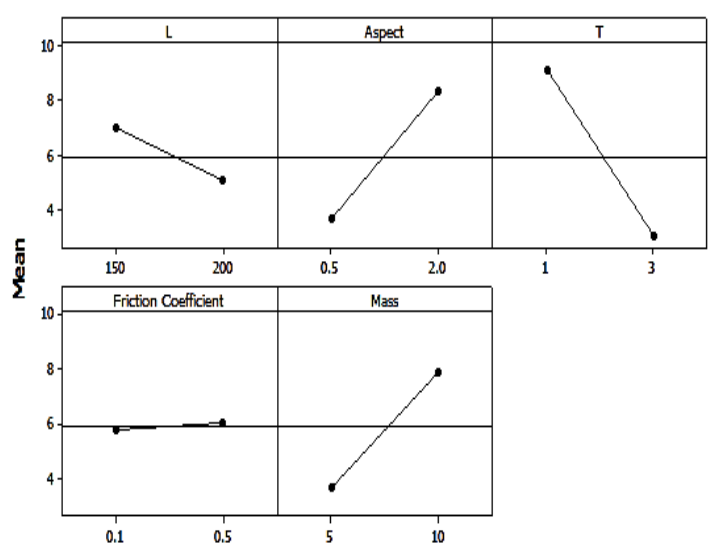

(a)

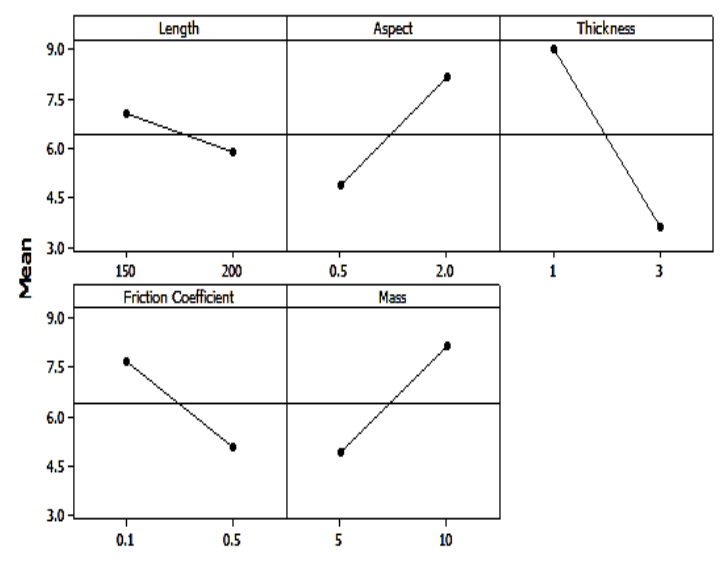

(b)

Figure 6. Main effects plot for SEA response for: (a) no trigger (b) with trigger.

To improve the crush distance, crush time and SEA, the tube's length and aspect ratio have to be increased. This is also achievable by reducing the wall thickness. On the 
other hand, to reduce the peak force, the length and aspect ratio should be increased. This is also possible by reducing the wall thickness.

\section{CONCLUSIONS}

The summary of the results is as follows:

i) The significant outcome is increasing the SEA in the trigger tubes for both aspect ratios 0.5 and 2 (that is, introducing 12 and 8 holes as the trigger, respectively) compared with conventional tubes. The trigger mechanism is designed to control the energy absorbing capacity for the tubes and also to shape tubular structures under dynamic loading conditions.

ii) Impact mass affects the maximum crush distance. Increasing the striking mass causes the crush distance and energy absorption to rise, while no change is shown in the initial peak force and dynamic loading. This signifies that colliding with a heavier mass only causes extra deformation, with an insignificant increase in the peak load.

iii) Increasing the length for conventional tubes does not affect the dynamic loading and energy absorption capacity for the structures. But, the trend is totally different for trigger tubes. When a tube with the aspect ratio 0.5 is considered, the shorter tubes $(150 \mathrm{~mm})$ show lower values of dynamic loading, while for the aspect ratio 2 the shorter structures indicate higher dynamic loadings.

Finally, based on the interaction of factors, it can be concluded that a guide for a better energy absorbing tube should be in the area of increasing the length of the tube and the aspect ratio, followed by reducing the thickness of the tube.

\section{ACKNOWLEDGMENTS}

The authors would like to thanks to Universiti Tenaga Nasional, Malaysia for providing laboratory facilities and financial support.

\section{REFERENCES}

[1] Olabi A-G, Morris E, Hashmi M. Metallic tube type energy absorbers: a synopsis. Thin-Walled Structures. 2007;45:706-26.

[2] Deb A, Mahendrakumar M, Chavan C, Karve J, Blankenburg D, Storen S. Design of an aluminium-based vehicle platform for front impact safety. International Journal of Impact Engineering. 2004;30:1055-79.

[3] Yamashita M, Kenmotsu H, Hattori T. Dynamic axial compression of aluminum hollow tubes with hat cross-section and buckling initiator using inertia force during impact. Thin-Walled Structures. 2012;50:37-44.

[4] Jensen $\varnothing$, Langseth $M$, Hopperstad O. Experimental investigations on the behaviour of short to long square aluminium tubes subjected to axial loading. International Journal of Impact Engineering. 2004;30:973-1003.

[5] Rossi A, Fawaz Z, Behdinan K. Numerical simulation of the axial collapse of thinwalled polygonal section tubes. Thin-walled structures. 2005;43:1646-61.

[6] Gupta N, Sheriff NM, Velmurugan R. Analysis of collapse behaviour of combined geometry metallic shells under axial impact. International Journal of Impact Engineering. 2008;35:731-41. 
[7] Al Galib D, Limam A. Experimental and numerical investigation of static and dynamic axial crushing of circular aluminum tubes. Thin-Walled Structures. 2004;42:1103-37.

[8] Lee S, Hahn C, Rhee M, Oh J-E. Effect of triggering on the energy absorption capacity of axially compressed aluminum tubes. Materials \& Design. 1999;20:3140.

[9] Niknejad A, Abedi MM, Liaghat GH, Nejad MZ. Prediction of the mean folding force during the axial compression in foam-filled grooved tubes by theoretical analysis. Materials \& Design. 2012;37:144-51.

[10] Zhang X, Huh H. Energy absorption of longitudinally grooved square tubes under axial compression. Thin-Walled Structures. 2009;47:1469-77.

[11] Zhang X, Tian Q, Yu T. Axial crushing of circular tubes with buckling initiators. Thin-Walled Structures. 2009;47:788-97.

[12] Chen D, Ozaki S. Circumferential strain concentration in axial crushing of cylindrical and square tubes with corrugated surfaces. Thin-Walled Structures. 2009; 47:547-54.

[13] Ghamarian A, Abadi MT. Axial crushing analysis of end-capped circular tubes. Thin-Walled Structures. 2011;49:743-52.

[14] Yamashita M, Kenmotsu H, Hattori T. Dynamic crush behavior of adhesivebonded aluminum tubular structure - Experiment and numerical simulation. ThinWalled Structures. 2013;69:45-53.

[15] Langseth M, Hopperstad O, Berstad T. Crashworthiness of aluminium extrusions: validation of numerical simulation, effect of mass ratio and impact velocity. International Journal of Impact Engineering. 1999;22:829-54.

[16] Alghamdi A, Aljawi A, Abu-Mansour T-N. Modes of axial collapse of unconstrained capped frusta. International Journal of Mechanical Sciences. 2002;44:1145-61.

[17] Salehghaffari S, Tajdari M, Panahi M, Mokhtarnezhad F. Attempts to improve energy absorption characteristics of circular metal tubes subjected to axial loading. Thin-Walled Structures. 2010;48:379-90.

[18] Bambach M. Axial capacity and crushing behavior of metal-fiber square tubesSteel, stainless steel and aluminum with CFRP. Composites Part B: Engineering. 2010;41:550-9.

[19] Hong W, Jin F, Zhou J, Xia Z, Xu Y, Yang L, et al. Quasi-static axial compression of triangular steel tubes. Thin-Walled Structures. 2013;62:10-7.

[20] Mamalis A, Manolakos D, Ioannidis M, Chronopoulos D, Kostazos P. On the crashworthiness of composite rectangular thin-walled tubes internally reinforced with aluminium or polymeric foams: Experimental and numerical simulation. Composite Structures. 2009;89:416-23.

[21] Kashani MH, Alavijeh HS, Akbarshahi H, Shakeri M. Bitubular square tubes with different arrangements under quasi-static axial compression loading. Materials \& Design. 2013;51:1095-103.

[22] Zhang X, Cheng G, You Z, Zhang H. Energy absorption of axially compressed thin-walled square tubes with patterns. Thin-Walled Structures. 2007;45:737-46.

[23] Zhang X, Huh H. Crushing analysis of polygonal columns and angle elements. International Journal of Impact Engineering. 2010;37:441-51.

[24] Li Z, Yu J, Guo L. Deformation and energy absorption of aluminum foam-filled tubes subjected to oblique loading. International Journal of Mechanical Sciences. 2012;54:48-56. 
[25] Gameiro C, Cirne J. Dynamic axial crushing of short to long circular aluminium tubes with agglomerate cork filler. International Journal of Mechanical Sciences. 2007;49:1029-37.

[26] Tarlochan F, Samer F, Hamouda A, Ramesh S, Khalid K. Design of thin wall structures for energy absorption applications: Enhancement of crashworthiness due to axial and oblique impact forces. Thin-Walled Structures. 2013;71:7-17.

[27] Ahmad Z, Thambiratnam DP. Dynamic computer simulation and energy absorption of foam-filled conical tubes under axial impact loading. Computers \& Structures. 2009;87:186-97.

[28] Theobald M, Nurick G. Experimental and numerical analysis of tube-core claddings under blast loads. International Journal of Impact Engineering. 2010;37:333-48.

[29] Karagiozova D, Jones N. Dynamic buckling of elastic-plastic square tubes under axial impact - II: structural response. International Journal of Impact Engineering. 2004;30:167-92.

[30] Najafi A, Rais-Rohani M. Influence of cross-sectional geometry on crush characteristics of multi-cell prismatic columns. Proceedings of the 49th AIAA/ASME/ASCE/AHS/ASC Structures, Structural Dynamics and Materials Conference; 2008. 